\title{
Digital Library and Intellectual Issues-Issues in Copyright and Intellectual Property
}

\author{
Mohammad Niqresh ${ }^{1}$ \\ ${ }^{1}$ Princess Alia University College, Al Balqa Applied University, Jordan \\ Correspondence: Mohammad Niqresh, Princess Alia University College, Al Balqa Applied University, Jordan.
}

Received: August 8, 2018

doi:10.5539/ies.v12n1p114
Accepted: September 11, $2018 \quad$ Online Published: December 28, 2018

URL: https://doi.org/10.5539/ies.v12n1p114

\begin{abstract}
The study aims at identifying the concept of digital library, it also tries to shed the light on the most significant intellectual issues by presenting its definition, development, functions (selection and acquisition of information resources from the web, sources indexing, communication and management of intellectual property rights, production of electronic resources and its availability, and digital resources maintaining), characteristics, and the purpose of turning into digital library, passed by the proposed stages of digital library transition, Types of Intellectual Property (Copyright, Patents, Trademarks, Commercial Secrets), it also discusses copyrights and intellectual property, the problems and challenges of digital library, and finally the future of digital library. Many researchers agree that the main objective of the digital library is to accomplish all the functions of the traditional library, but in the form of electronic digital libraries which are only an extension for jobs that are performed and the resources that are accessible in digital library. The study concluded that digital libraries emerged as an obligatory result of revolution of the third millennium which is called the communications revolution, as libraries are able to prove that they are able to stand and cope with all the modern technology, where there is no conflict between the new and modern trends in libraries issue, but it also benefits from both of them concerning their evolution instruments in service for beneficiaries in every time and place.
\end{abstract}

Keywords: digital library, property rights, intellectual issues

\section{Introduction}

Informative revolution era has left remarkable effects on all society sectors, including libraries that cannot fall behind spirit of the age neither it will move away from its characteristics and attributes because it is one of the scientific, cultural and educational institutions that is important in contemporary society.

Libraries currently have undergone a great quality advancement which constitutes a significant shift in its services as well as nature of the information that it provided and their beneficiaries where these libraries turn from traditional to hybrid ones by Combining between the traditional and modern digital forms, or to the digital libraries as concluded in a study by Abdul Hameed (2008). It could be argued that the Digital Library is considered one form the Modern Libraries where its dependence will be on modern technologies in conversion the information and data to digital format for achieving greater effectiveness and efficiency in storage and processing of information and then transmitting them.

Digital Library emerged through the initiative on a project for digital libraries funded by (NOAA) Space United States of America in the year (1994) which have been allocated an amount of 24.4 million for six American universities in order to start a research project for taking an advantage of tremendous development of the internet, and accordingly, there has been an adoption of the term known as "Digital Library" through Computer specialist as well as librarians (Faraj, 2005).

In spite of the widespread use of the internet in the informative age, the pioneers of digital libraries that a lot of important human knowledge still retain paper form and see the need to exploit technological opportunities available to be converted into digital format, any digital libraries, and among them was Troy Williams, CEO and founder of the site question, which is today the largest digital library of a commercial nature in the world (Saracevic, 2001).

The successful experiences of digital libraries projects are purified on a global scale where some universities in America and Europe have already succeeded in field of digital libraries on a high level of quality and even at the 
Arab level, we rarely find some experiences that do not exceed the fingers of your hands, but serious attempts have been executed to keep up with the latest progress with digital global trends projects at the Arab level library such as: Aloariq Smart Village and Digital Library of Alexandria working to achieve progress in the field of digitization of humanitarian Heritage and other experiments that are needed for all of them to a separate position to deal about this experience.

The digital library offers digital and realistic solutions for many of the problems of the community to become able to keep up with western civilization and the East as an instrument for economic, social development and scientific research, it is through digital libraries information services could be provided to remote areas as well as to improve level of services while providing real elements of basic services for daily information or on the society information (Al-Jowheri \& Al-Hazmi, 2008).

\subsection{Research Problem}

Personal libraries are no longer with development of science and prevalence of knowledge are able to respond to universal coverage based on the scientists and researchers interests as well as the high cost of books, sources of science and valuable references which reduced much of the desire or the ability to build libraries, in the personal libraries, the dependence is only on the information available online, on the other hand, in addition to obsolescence of information besides change of importance sources within a short period of time for fields of scientific knowledge, many of them led to dispense the idea of establishing personal libraries.

In the past few years, many academic and specialized libraries in the west attempt to shift from traditional libraries to digital ones where the first of these libraries appeared on the internet in 1995 but the transformation in the field of library and information in the Arab world is still below the required level, therefore, this research aims to identify the digital library concept and its application through the study of all aspects of this matter and the necessary procedures to ensure that processes to comprehend the needs of digital libraries, as this research attempts to identify the challenges and changes in the field of digital libraries.

\subsection{Research Objective}

The research aims at identifying the concept of digital library, it also tries to shed the light on the most significant intellectual issues by presenting its definition, development, characteristics, and the purpose of turning into digital library, passed by the proposed stages of digital library transition, it also discusses copyrights and intellectual property, the problems and challenges of digital library, and finally the future of digital library.

\subsection{Importance of the Study}

The importance of this study emerged from the confirmation of general orientation nowadays for shifting to the electronic world and digital content where pursuit to the field of library and information which is hard to come up with the advantage of applications of new technologies in the field of computers and information system technologies, as well as communication systems and their applications for proving that the field of libraries and information has not disappeared, but rather it tries to closely pursue with latest developments.

Moreover, this research attempts to shed light on the significance of digital libraries in terms of their quest to revitalize movement of scientific research and its contribution to solving the most important issues at the field of research which is compiling sources of information, and access mechanism more quickly than traditional ones, as well as being a digital transportable library where the researcher can carry with him everything that he needs from the sources and wherever he goes, whether by using of a laptop or laser disks and in this way, the time and place factors shall not restrict the mental activities. This study also is important through contributions which are expected to be added based on the recommendations and solutions that will be proposed by the present research.

\section{Literature Review}

\subsection{Theoretical Framework}

Many concepts, definitions and modern titles were set for digital library, and these names are as follows: Electronic Library, Virtual Library, Hybrid library, Library of future, Digital Library, Library without Wall and On-Line Library. Despite the large number of terms but only three terms are used where they are considered the most common ones: Electronic Library - Virtual Library - Digital Library (Abdel Hameed, 2008).

The term Digital is referred to data that were transmitted as intermittent and unconnected electrical pulses represented by dual numbers (Zero and one) where digitalization refers to process of converting data into information systems which means converting any printed text or image into digital signals using some types of skimming devices (Al-Jowheri \& Al-Hazmi, 2008).

Additionally, there are other terms which are used as information management centers, Desktop Libraries, 
Networked Libraries, and Centers Libraries, where it is important to indicate that all of these libraries with regardless to their different titles depend on using the latest information technology, communications, programming and computers operations where their main concentration are based on the idea of availability and service (Faraj, 2009; Hassanein, 2008).

The intellectual production of information sciences is rich with many definitions for concept of "Digital Library". Collier (1997) defined it as information storage and retrieving regardless to their contents whether it is text or sound as it is available on distributed network.

While, Arms (2000) defines "Digital Library" as the libraries that handle all of operations machinery or digitally including the missions that implemented by specialist individuals in traditional libraries among them (Selection), Indexing and searching about information in addition to reference services ... etc. whereas each one of these services require a specified intellectual activity by those who work at this field which the computer may find it difficult.

Consequently, Abu Lofah (2005) defined "Digital Library" as the one which maintains digital information sources whether the produced original ones or those that transferred to digital form, as their operations are controlled automatically by using a machinery system as it can be available through computers network whether it is local expended or via internet.

Subsequently, Rosenberg (2005) defines "Digital Library" as transferring the traditional library books to a digital image through the scanning or entering it as an electronic text.

Moreover, Faraj (2005) defined "Digital Library" as a term used for describing every attempt concerning an access to indexes online towards the information at the library.

Furthermore, Faraj (2009) defined "Digital Library" as a group of electronic or digital information items available on the library (Server) where it can be reached through local network or the common on Internet.

Additionally, the digital libraries term is interfered with the term "Virtual Libraries", but they are different since that virtual libraries are actual ones where there are web sites designed for them on the internet for being three-dimensional environment which allow to their users for priceless login to them, as well as benefiting from their information from remote excess where it is probably the specialization for the narrow objective sources of available information which distinguished virtual libraries which maintain the comprehensive coverage concept (Zuhairi, 2004).

\subsection{Previous Studies}

In a study conducted by Al-Omran (2010) entitled "Digital Library and Protection of Copyright and Intellectual Property", he followed the development of academic libraries and the direction of digital libraries and the obstacles encountered, including copyright and intellectual property, and calls for reviewing legislation in line with developments in this field .

Abu Izza (2006) conducted a study entitled "Trends of Arab researchers towards open archives and periodicals available free of charge through the Internet: Arab faculty members at Sultan Qaboos University as a model". The study examined the attitudes of Arab researchers at Sultan Qaboos University toward the new model of scientific communication based on free access to information published on the web. The study population consisted of (60) researchers from a variety of disciplines. The researcher found that the Arab researcher at Sultan Qaboos University has not yet realized the concept of free access to scientific information, that researchers accept the free access model is still weak, and that $78.8 \%$ of the students did not publish research in the free magazines and $77.8 \%$ of them are not familiar with international initiatives on free access, and among the researchers the reasons for their refusal to publish in electronic journals available free of charge that the editorial board of patrols unknown to them, and $75 \%$ of them believe that the articles published in these periodicals are not recognized by the academic committees, and $50 \%$ of them believe that publishing in free periodicals offers only slim chances to get grants in search.

El Sayed (2008) conducted a study entitled "Self archiving as a conduit for knowledge communication on the web: A study of its library and information applications". In this study she investigated the attitudes of faculty members in the Arab libraries and information departments towards making available a quantitative form of their scientific production in their personal institutional or non-institutional locations, and identifying the general features of this intellectual production available on their personal websites, while discussing issues related to self-archiving such as publishers' policies and self-archiving, where self-archiving is included in its various methods, free access also includes free access patrols, self-archiving is a means of free access. 
Shaheen (2009) conducted a study entitled "Initiatives of Free Access to Knowledge; A Documentary Study of the Frameworks for an Arab Initiative". The researcher stressed that access to knowledge means access to power. There are three basic pillars of free access to knowledge: publishing + support and assistance + archiving, and all that is published from the principle of access and free access is available free of charge to the whole world for reading, downloading, copying, distributing and use adjective by identifying the author, publisher or product by any desirable method. There is no need for permits or licenses; free access to OA movement is an international movement for the use of the internet to unlock closed doors of knowledge. The beginning of the global movement of free access to knowledge from the World Summit on the Information Society (2003-2005), which called for universal access to scientific knowledge on the basis of equal opportunities for all and the development and dissemination of scientific and technical information, including open access initiatives for scientific dissemination, facilitating access, including free and affordable access to scientific journals, open books for free access, and open archives of scientific information. The study examined many global and Arab initiatives in the same field. At the end of his research, the researcher proposed a set of key elements of an Arab initiative for free access to knowledge.

Atmizi (2010) conducted a study entitled "A flexible framework for evaluating the contents and activities of electronic courses supported and integrated in Arab universities". The research shows the nature of e-learning, e-learning platforms and e-courses. A flexible framework for evaluation was provided, which allows universities to use it according to their specificity, according to the nature of the courses and the approved e-learning platform. Where the contents, the activities required, and the reasons for them; and finally explained how to use this framework.

Harley et al. (2010) conducted an online exploratory survey of faculty members' expectations for free textbooks available free of charge or for a small fee. It aims to reveal the views, perspectives and expectations of the teaching staff and their attitudes in this field, as well as the extent of acceptance of students and their willingness to deal with the electronic environment and other affecting variables.

\section{Research Methodology}

The researcher adopted a theoretical approach because it is the most appropriate method through reviewing the related literatures and contents.

\subsection{Development of Digital Libraries}

Development of digital libraries refers to a long time ago since the 30s of the last century for the emergence of the idea of "World Encyclopedia" by (Wales, 1938) where it is possible to say that the main reason for emerging this type of libraries is the great growth in information technology, communications, specifically the internet as well as discovering the language of (HTML) or the language for determining the transcendent text which has quickly spread for easy handling through a variety of programs and instruments such as text editing as (Microsoft word) where it depends on Tags structuring the text in paragraphs form, lists and magnificent links, besides designing of "Tim Lee Burns" for the internet (WWW Worldwide Web) or what is called global spider structure which resulted to the necessity for creating the data and information in a digital electronic form instead of the traditional one whereas many supporting corporations afterwards in establishing initiative projects such as Digital Libraries Initiative, then this is followed by a number of initiatives in the field of digitization of intellectual production as included by a study conducted by (Meselhi, 2004; Hassanein, 2008).

It is probably that the first attempts in field of active and computerized library services began in early fifties when Allen Kent and his team at the University of "Reserve Western University" in using the computer in information retrieval (Bouazza, 2006).

In the seventies and specifically in (1971), Michael Hart established the first digital library in contemporary history and called it "Project Gutenberg" as mortal inventor of printing in the fifteenth century, Michael Hart is the Gutenberg digital era in the site Project Gutenberg today focal point aims to provide internet users of more than trillion of text files by the end of 2001, despite the massive amounts of available files within a site project Gutenberg, and it did not contain many of the features that could make it a digital library which is complete and such as possibility of text search or bookmaking of books or simple search instrument and the reason for that is Hart goal from the beginning to put the largest amount on the network regardless the technical aspects of the sites (Keller, 2009 ).

In the eighties, integrated information systems emerged which are used in libraries management and data processing where indexing operation computerization has been executed as well as periodicals besides other issues. Afterwards, the libraries started maintain the electronic contents and consider them as undivided part of 
their groups and with proliferation of CDs, the access methods for information obtaining has changed from availability Online to the one on the internet (Bouazza, 2006).

In a study conducted by Choudhury, Hobbs, and Lorie (2002) they concluded that during early nineties, a project "Wyre Tap "emerged which uses technology of Gopher for processing folders via internet and it contains specialized digital texts such as: Treaties, international laws, technical and military documentation. In 1993, John Aukrblom began working on an index called "Online Books Page" includes access to all online books available at the Internet including Gontnrberg project.

Two basic stages are specified regarding digital libraries history as indicated by a study conducted by Bouazza (2006) as follows:

The First Stage: Some institutions such as the National Science Foundation (NSF) and (NASA) contributed effectively in financing research projects at early and mid- nineties have a positive impact for clarifying the concepts related to digital libraries along with providing definitions which led to this stage to make progress in the field of "Digital Library".

The Second Stage: The second phase is a support for the first one which covers the following issues such as: Audio tapes, musical, economic data, software, video, and textual materials as well as (Anthropological models), in addition to images and literary manuscripts. The history of digital library is the same for developing usage of modern communications technologies and its revolution in the field of libraries and information as digital library is embodiment for the libraries value which depends in all of their operations on modern technologies such as computers and communications networks technology (Hassanein, 2008).

\subsection{Specifications of Digital Library}

At first, it should be noted that most of the differences that are characterized by digital libraries for computerized libraries are limited in storage and indexing sources, bookmaking and therefore, decreased the budget of published sources digitally as well as abundance of information or to participate in the information network (Gladney et al., 1994), as digital library is distinguished by some important features as clarified on the following table:

Table 1. Differences between traditional and digital libraries

\begin{tabular}{|c|c|c|}
\hline $\begin{array}{l}\text { Serial } \\
\text { No. }\end{array}$ & Digital Libraries & Traditional Libraries \\
\hline 1 & Dynamic and Reflect High Imagination & Immutable and Develops Slowly. \\
\hline 2 & $\begin{array}{l}\text { Dual contact accompanied by simultaneous and rich } \\
\text { interaction. }\end{array}$ & Normally, slow and unilateral interaction. \\
\hline 3 & $\begin{array}{l}\text { Digital libraries can support an alternative } \\
\text { philosophy: free and atelier at the same time. }\end{array}$ & They support the tradition of free and universal access. \\
\hline 4 & $\begin{array}{l}\text { Digital contents consist of multimedia with variety } \\
\text { multimedia sizes; they are divided and are not } \\
\text { well-defined. }\end{array}$ & $\begin{array}{l}\text { The content originally consists of text and singular printed and text } \\
\text { information where their contents groups are well-defined, however, it } \\
\text { remains not directly related to the way that reflects the dynamic. }\end{array}$ \\
\hline 5 & $\begin{array}{l}\text { It is similar to (scaffolding) at the internal level data } \\
\text { standard enriched according to the context. }\end{array}$ & $\begin{array}{l}\text { It seems that the content is extended for its structure, as the standard data } \\
\text { (metadata) is very limited. }\end{array}$ \\
\hline 6 & $\begin{array}{l}\text { The content is not limited in the content that has } \\
\text { academic nature but it gains its reliability from its } \\
\text { usage. }\end{array}$ & $\begin{array}{l}\text { It seems that the content has more academic nature (scholarly), as it } \\
\text { resulted from its evaluation and revision before its publication. }\end{array}$ \\
\hline 7 & $\begin{array}{l}\text { Access methods to information are not limited by } \\
\text { default added to management of distributed groups } \\
\text { who are controlled in the same way. }\end{array}$ & $\begin{array}{l}\text { Access methods to information are limited as they are added to central } \\
\text { management for content and groups. }\end{array}$ \\
\hline 8 & $\begin{array}{l}\text { It is possible to separate between the physical aspect } \\
\text { of the content and its organization which allows for } \\
\text { establishing digital groups. }\end{array}$ & $\begin{array}{l}\text { It can be controlled directly in the organization of the physical and logical } \\
\text { linking of groups and the relationship between them. }\end{array}$ \\
\hline
\end{tabular}

Al-Jowheri and Al-Hazmi (2008) and Abu Lofah (2005) added that digital library carries its groups to beneficiary wherever, there is a computer connected to Internet as well as benefiting from possibility of computers capabilities in retrieval and reviewing the information, besides updating them along with making it available permanently in various ways such as (Text-Images-Audio), in addition to increasing efficiency, developing performance in technical operations, information services, as well reducing some of routine works which will help in utilization of 
librarians assistants time besides easy administration and quick access to information regarding organization, storing and updating of data and information.

Comparison between traditional and digital libraries, it is no doubt that digital libraries are distinguished from the other ones in many aspects (Hassanein, 2008, Abdel Hameed, 2008) as follows:

- Saving the researchers' time and overcoming spatial and temporal barriers between the countries, the researcher does not need to get into what information to travel or like that. This is an application of the principle that information reaches the beneficiaries.

- Ability to control the content and electronic sources of information, where information and data can be organized, stored and saved in ways that are accurate as effective as they can be easily updated.

- Utilization of great potential for digital libraries and technologies in terms of the correlation information and the use of Multimedia and Hypertext which enable the researcher an access to information as much as he needs about his research subject.

- Possibility of participating in electronic sources in sharing digital and resources between libraries. This document can read or use the information from source of more than a researcher at the same time, which increases effectiveness of information source and increasing the benefit from it.

- Facilitating borrowing operations between libraries and various information institutions, in addition to increasing cooperation between the libraries in various fields for achieving a better level of services provision to beneficiaries, besides enhancing communication with various information facilities in quick and guaranteed means.

- Strengthening the role of electronic resources and indicating its importance in terms of the preparation quickness, production, exchange of information and data via the World Wide Web.

- Getting the libraries and information centers from their locations to libraries without walls, where the beneficiary can access to his content from anywhere around the world.

- Keep pace with technical progress and the information revolution and exploitation in the field of library and information.

\subsection{Objective of Transition to Digital Library}

Many researchers agree that the main objective of the digital library is to accomplish all the functions of the traditional library, but in the form of electronic digital libraries which are only an extension for jobs that are performed and the resources that are accessible in digital library. As an example, borrowing books at traditional library shall disappear as such problem is resulted from limited copies, in addition that the digital library will redefine the libraries services and design them to achieve basic objectives for "The Library" more effectively than it is now (Faraj, 2009).

Collier (1997) stated that the libraries achieve two main objectives through transition to digital libraries, specifically keeping sources of information digitally and providing sources of information in the library for users anywhere and anytime, without any cost.

The objectives of the digital library are represented in producing and benefiting from the knowledge which make communities more efficient and productive, and it also enhancing the degree of cooperation between the sectors of research and education and facilitating establishment of new communities at those sectors (Keller, 2009).

\subsection{Functions of Digital Library}

In the midst of this digital environment, the traditional functions currently experiencing a change in form but not in terms of origin, that is the functions of the library will focus on groups of more than electronic digital collections and the subsequent provision of services for the public, and the most prominent functions carried out by digital library as stated by Bouazza (2006) are as follows:

\subsubsection{Selection and Acquisition of Information Resources from the Web}

Digital libraries identify beneficiaries who enter the library site on the web through a number of visits and their activity and the information they request in relation to selection of the source, library informs about important electronic resources by the library site where this is done by so-called due information diligence, which means to ensure that the permanent pursuit of these electronic resources, whether what emerges from new resources or what occurs to existing ones from developments. 


\subsubsection{Sources Indexing}

Digital libraries process indexing of public information sources available to the beneficiaries' online and set the links.

\subsubsection{Communication and Management of Intellectual Property Rights}

Library is concerned with rights of the electronic resources which information institution provides for the beneficiaries whether it's in the form of CDs or resources available on the Web (signing contracts with publishers and distributors).

\subsubsection{Production of Electronic Resources and its Availability}

Digital libraries publishes available paper content digitization and makes it ready for beneficiaries usage, where in such cases the information specialist became a publisher who follows up digitization operation as he chooses texts as well as surveys them and takes into account the intellectual property aspects for each document and ways to make them available for usage.

\subsubsection{Digital Resources Maintaining}

Digital library maintains digital resources because of the risks to which can cause their loss, for example some digital texts disappear since it can no longer be read due to changing of coding methods and emergence of new standards for recognition of the characters, so the information specialist are invited to re-register the digital information on a regular basis for the new contents according to latest version of the software so keep these data readable.

\subsection{Reasons for Emergence of the Digital Library}

There have been many factors that showed compelling need for emergence of digital formats and contents sources of digital information, there are a number of reasons, which calls for establishment of digital library (Abdel Hameed, 2008) including the following:

1) Spreading of the Internet and its availability for many beneficiaries.

2) Need for developing and delivering services in a faster and a better way.

3) Existence of many information contents in digital form and they are available commercially.

4) Existence of appropriate technology with acceptable cost.

Hassanein (2008) indicated that there are interrelated factors that led to emergence of the need for digital libraries or general sense to the appearance of digital forms or electronic information sources, and these factors as follows:

- Technological development and communications revolution nowadays and depending mainly on information networks and the Internet to get information.

- Huge and steady increase in intellectual production resulting from scientific research all over the world.

- Lack of qualified human resources to accomplish the technical operations on media information such as: indexing, bookmaking and other technical operations.

- Need for developing the services provided by libraries and information centers with accomplishing them on the time and effort of beneficiaries.

- Non-availability of material resources of the libraries represented in traditional limited financial budgets in libraries.

- Non-availability of space at traditional libraries that enable the library to acquire all of the issued publications in event of budget provides for purchase.

- Increasing in cost of printing publications to higher prices of printing materials, making the traditional publishing career expensive with parallel to easy dissemination of material electronically on Internet in digital form.

\subsection{Elements of Digital Library}

Abu Lofah (2005) indicated that the digital library consists of three main levels as follows: Public library catalog, connect to its services and borrowing requests, second element includes a digital content such as : databases, digital books and magazines and the third element consists interactive services such as: technical support and answer queries and current awareness, news and other issues.

Faraj (2009) added that Library properties which have been converted to a digital image as follows: 
1) Electronic books.

2) Data collection purchased on CDs.

3) Data collection purchased Online.

4) Electronic publications with the corresponding paperwork.

5) Electronic publications that do not have corresponding paperwork.

6) Electronic reference works, which increases continuously and that do not have corresponding paperwork.

Arms (2000) mentioned that stored information at digital library are stored as digital entities which is about a group of units of small digital but this definition is very simple as the contents of the entities basic digital have a particular building and some of the information is to be attached to them, such as rights of intellectual and Figure (1) illustrates that digital entities consist of two parts which are the content and attached data that sometimes called data descriptions.

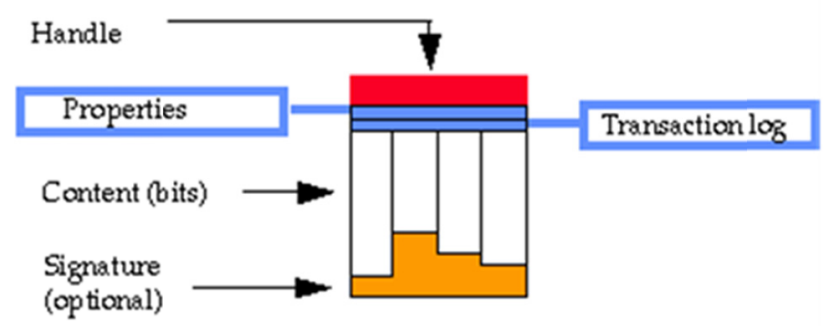

Figure 1. Digital library entities

To enable the content to represent useful information, its type must be known. Consequently part of the content may be of type text (perhaps encoded in a mark-up language), while another part may be of type audio. A single digital object may contain many types of content. It turns out that arbitrarily complex data types can be constructed from a few basic types, notably bit-sequences, handles and other digital objects. By combining these in various combinations, any digital content can be represented (Arms, 2000).

Digital works in computer are represented by software, databases, integrated Circuits either in digital environment at the web site content material from electronic publishing texts and audio-visual materials (Al-Khatib, 2001).

\subsection{Stages of the Proposed Projects in Digital Libraries}

Areas that need to be counted addressed and studied before starting work for transition projects to digitalization Hassanein (2008) as follows:

\subsubsection{Goals and Extent of Digitalization Project}

1) The first step for transition to digital library is to understand the library objectives where digitalization project requires a lot of effort and determining the time and high costs. Therefore, it is necessary to identify the goals and the desired objectives for digitalization project before starting it as a vision of beneficiary or not of the project is to be clarified besides taking appropriate decision in this regard.

2) The Targeted Audience of Digitalization Project

The step for identifying the targeted audience of the digital project is considered, a complementary point for the objectives of the project which will help officials in planning and determining the desired objectives once the availability of digital materials on the Internet for emerging other categories of beneficiaries

\section{3) Analysis of Collective Materials}

This stage is represented in testing, analysis of materials, sources of information as well as identifying materials to be digitized in order to achieve the desired goals of the project through the best choice of materials.

\section{4) Needs Analysis}

This step is represented in identifying digitalization projects by taking a sample from project environment and available resources for specifying needs requirements which indicate determining project finance resources as well as assigning the required jobs to work at the project along with classifying type and extent of available technical 
support for the project.

\section{5) Cost Analysis of Digitalization Project}

This step is represented in conducting the financial analysis for the project and its impact on budget of supporting corporation for digitalization projects including the project costs, hardware, software, staff wages, training costs, presentation and preservation costs.

\section{6) Adoption of Standards and Processes}

Specification of image and scanning are considered the most important considerations that must be taken into account by the organizers of the digitization project,whenever the standards and specifications most specifically effect on reducing the time factor and the cost of the project, on the operators of the project to pursue the best ways . Methods and practices adopted in the process of digitization as well as progress of the work flow in the project.

\section{7) Documentation}

Documentation of the strategies serves as very important points in planning for the upcoming projects, which include details for directing the project sound guidance and avoid a reoccurrence of the problems and their solutions.

\section{8) Evaluation}

Evaluation process is counted as the final step in process of planning for digitization projects, besides, it is a special assessment of the project to see how its goals are achieved where the process of evaluation of the project and its instruments must be an essential aspect of the project planning operation which allows evaluation for reconsidering the policies that can be right besides, taking an advantage of mistakes and lessons for improving actions of the current projects.

\subsection{Digital Library and Intellectual Property}

Many scholars agreed upon that protection and management of intellectual property rights of digital content has not yet achieved the level of required security, despite major developments in field of technology for books and digital libraries where the remains of easy piracy of books by breaking the encryption lot of these instruments, which will prevent the authors from writing and publishing as such a procedures will reduce scientific production (Adam \& Seamus, 2008).

As the effects of the presence of free services to download large numbers of files calculated without the presence of a minimum of regulation and legalization advocates intellectual property protection to the need for the existence of laws and stringent legislation regulating this process, if some of these libraries do not have basically the confiscation of digital making it out of laws for ensuring copyright protection and intellectual property (Fox \& Urs, 2002).

The intellectual property protection to all works resulting from the explosion of technological ethical issues affected by the information community, where modern technology legal system after it was put forward many problems suffered by the protection of information in the digital environment (Alawi, 2007).

\subsection{Copyright and Intellectual Property}

Alawi (2007) defines intellectual property as products of moral or intellectual nature, where there is difficulty in protecting imaginative or moral productions and it is often that intellectual property interprets as copyright or publishing and related to its attachments including production rights or radio and the goal of these rights for providing information for sake of the knowledge.

Mustafa (2009) defines intellectual property as the rights enjoyed by the people for use of the exclusive production of their ideas for a specific period of time.

It is possible that the potential source resentment interested in protection of intellectual property in process of broadcast digital sources at the site of the library is probability that the beneficiary in irregular work such as: changing the file information or stealing books or a changing in contents of the sources of information or digital download information source digital library on the network, which grants him full ownership (Choudhury, Hobbs, $\&$ Lorie, 2002).

Legal protection issue for intellectual property rights in an environment of digital library arises many inquiries starting from identification of intellectual property rights in an environment of digital library as well as identifying digital works such as: protection and applying the capacity of the existing rules within legislation to provide protection for these rights online environment, and these issues are still controversial but they are under 
consideration by legislators (Yousef, 2005).

\subsection{Types of Intellectual Property}

Wahdan (2001) stated that there are four types of intellectual property protection on the Internet specifically as follows:

\subsubsection{Copyright}

It protects majority of the laws, the original work of authorship of illegal use or reprinting illegal modification or distribution, and it also protects the right to express views.

\subsubsection{Patents}

It protects laws of good inventions and useful processes, such as: operations, machinery and production.

\subsubsection{Trademarks}

The Laws protect trademarks, words, names or symbols used to identify companies, commodity products and distinguish them from other ones.

\subsubsection{Commercial Secrets}

Commercial secret information is used in the work which gives its owner characteristics other than others about how it can be recognized and used with spread of information technology appeared another type of intellectual property, which is represented in digital bookmaking. Alawi (2007) stated that, there are many of legal problems of computers and communications world which can be summarized into three fields:

Domain (A): Internet contracts problems starting from participation contracts including Internet sites contracts (Contracts of Services Requisitions and Electronic Promotion).

Domain (B): Problems of protecting the rights of users and dealers in the online environment as well as the systems of consumer rights, in addition, to protection of the right to private life and property rights.

Domain (C): Problems related to information security for users or Web Sites. As the digital entities contain intellectual acts that have values, the storage shapes includes information which allows managing the entities through economic and social framework where the stores maintain this information besides providing basic reference information as well in addition to assuring security for these entities for securing the legal application of digital entities whereas the stores internal organization. As method of storing digital entities be unknown by beneficiary where there is a special protocol called "Protocol for Warehouse Availability ", since that the main orders in this protocol allows digital entities and their special specifications service requisitions besides providing orders for addition and cancelation of them (Arms, 1995).

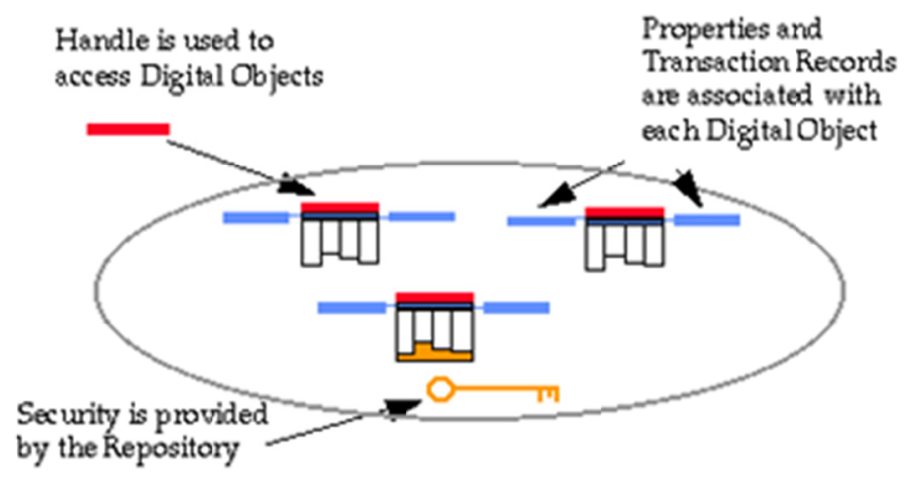

Figure 2. Protocol for warehouse availability 
Table 2. List of intellectual property legislations in field of technology in certain Arab countries

\begin{tabular}{|c|c|c|}
\hline $\begin{array}{l}\text { Foundation } \\
\text { Year }\end{array}$ & State & Legislations, Date of Enactment, Re-enactment and their Amendments \\
\hline 1992 & Jordan & $\begin{array}{l}\text { Law No. } 22 \text { of } 1992 \text { law of copyright protection, as amended by Laws Numbers } 14 \text { of } 1998 \text { and } 29 \text { of } 1999 \text { as it } \\
\text { includes protection of software and databases. } \\
\text { Protection Act designs of integrated circuits No. } 10 \text { of } 2000\end{array}$ \\
\hline & U.A.E. & Federal Law No. 40 of 1992 and its implementing regulations including protection of computer programs \\
\hline 1993 & Bahrain & Law No. 10 of 1993 - Protection of computer software. \\
\hline 1994 & $\begin{array}{l}\text { Egypt } \\
\text { Tunisia }\end{array}$ & $\begin{array}{l}\text { Law } 29 \text { of } 1994 \text { amended for } 1954 \text { law including protection of computer programs and databases. } \\
\text { Law } 36 \text { of } 1994\end{array}$ \\
\hline 1995 & Qatar & Law 25 of 1995- Protection of computer programs. \\
\hline 1996 & Oman & Law 47 of 1995 \\
\hline 1999 & $\begin{array}{l}\text { Lebanon } \\
\text { Kuwait }\end{array}$ & $\begin{array}{l}\text { Law } 75 \text { of } 1995 \text { (Programs and databases) } \\
\text { Decree-Law No. } 5 \text { of } 1999 \text {, programs and databases }\end{array}$ \\
\hline
\end{tabular}

\subsection{Copy Right}

The legal framework should maintain to ensure that work in a file of the efforts as a documentation of attempts relating to rid the rights of the author identified with redefinition of the copyright owner and address of correspondence or contact with him and getting his approval to post the material within the project that may be required to pay a fee for the rights holders, especially in the case of projects profitability (Moflih, 2008).

Mustafa (2009) stated that Copyright and Neighboring Rights protect the computer programs and database according copyright throughout his life and after his death and those rights include the following:

\subsubsection{Moral Rights}

It is attributed to innovative idea into an innovative person who has the right to disclose all of the rights associated with one of the author and shall not be subject to the legal actions.

\subsubsection{Material Rights}

It is financial exploitation which represented by material benefit of intellectual production and creativity as it is a temporary right where his owner may dispose it as he wishes besides the author also has the right to exploit his bookmaking in any way.

Table 3. Rights of copyright

\begin{tabular}{cc}
\hline \multicolumn{2}{c}{ Rights of Copyright } \\
\hline Financial Rights & Moral Rights \\
\hline Right to produce (copies) of bookmaking & Right to Self-publishing of the Work \\
Right of public performance & Right of Bookmaking Percentage \\
Lending or borrowing Bookmaking & Right for Bookmaking respect \\
Following up Right & Right to withdraw Bookmaking from Distribution \\
\hline
\end{tabular}

Rosenberg (2005) stated that there are two basic conditions about maintaining copyright at digital libraries without prejudice to or waiver of copyright laws when implementing the Digital Library Project through protection of the rights of both authors and publishers upon establishing the digital library and providing those sources for use through the protection of digital projects themselves.

\subsection{Requirements for Establishment of Digital Library}

Establishment of a digital library must pass through several stages of the most important input information in the main functions of the library which includes: supply, indexing, lending and other computerization of most of its procedures and then digitalization the contents of the stories and turn them into attractive forms and animations. The most important requirements for establishment of digital library are as follows: (Abu Leif, Collier, 1997, 2005).

1) Legal and regulatory needs as the library upon converting the text of articles, researches, reports and essays into other forms of machine-readable should obtain special permission from the owner of the right owner in accordance with law of copyright and intellectual protection. 
2) Linking between electronic journals site with its periodicals that contained automated index system in the library and writing footnotes of the site electronic journals.

3) Strong financial support, which helps in implementing and operating the project. The digital libraries for their operation require certain policy and procedures especially in relation to some groups as Al-Maliki (2005) stated, for example:

a) Materials with capacity and strength in their capacities

There are libraries that have a great power in allocating their capacities and their sizes which made their full or partial digitalization an important matter and then adding new numbers to them.

b) Single Groups

In some libraries, there are unique single copies where digitalization shall be processed on them.

c) Preferences determined by the community of beneficiaries

These capacity preferences at some libraries justify maintaining them such as; their need in academic curricula, besides it is important in this regard to indicate some electronic surveys and digital material forms need big time and considerable effort in libraries characterized by enormity of their holdings.

- Technical Requirements

1) Hardware 2) Software including connecting protocols with Browsers 3) Communications networks and Internet terminals 4) Data bases and digital format 5) Storage media and information sources 6) The adoption of a particular format for data documentation and information sources (Extensible Markup language (XML) 7) User Interfaces 8) Software protection of intellectual property rights to information sources and digital documents 9) Software security, and to verify the identity of users of the digital library and data security and digital collections.

- Digital librarian

The human element is necessary to run the digital library operations regardless to technology and modernity of the digital library project but there are conflicts in human resources job titles who work at the digital library. Such jobs include the following: Librarian, Information Specialist, digital resources Librarian, Digital Resources coordinator, Library Specialist in digital collections, Managers of electronic or online archives.

- Materialistic Needs

It is necessary to provide necessary funds due to relatively high costs of for establishment of digital libraries in the Arab countries for nonexistence of required technology for establishing this kind of libraries.

\subsection{Problems Digital Library}

Libraries in general encounter in digital era series of challenges mentioned by Al-Maliki (2005), including: the information revolution that emerges every day even every hour massive amounts of information so that any library in the world cannot comprehend its self-sufficiency regardless of the potential physical, human resources and diversity of traditional information sources through audio-visual and electronic connection which the online library facing challenges related to digital quality (Guendhilji \& Al-Samurai, 2004). In spite of the shortcomings that plague arbitration of scientific researches, but it still remains a precondition for recognition of electronic publications and equality of printed works (Bouazza, 2006). In terms of lack of sufficient awareness of the digital transformation gains that would accrue to the beneficiaries themselves as it requires from the user training or researcher to use the available information and to deal with the Internet through various browsers (Abu Leif, 2005).

Digital libraries face many legal and technical problems, such as high material costs of the sources of digital information and technical equipment necessary for the transition (Rahouma.2005).

Some of digital libraries problems are as follows: Technological Obsolescence, Soft Solutions and Relational Queries For example, the methods of search and retrieve back to the 1970s and 1980s of the twentieth century (Abdel Hameed, 2008; Faraj, 2009; Hassanein, 2008).

Al-Maliki (2005), divided these difficulties into the following:

1) Difficulties of libraries, which are as follows

2) Lack of enough training and numbers of Librarians.

3) Problems related to digital libraries capacities.

4) Rejection of the idea of digital libraries by Librarians 


\section{Findings and Recommendations}

The trend towards a digital society by the communications revolution is considered a movement sweeping to volume of scientific and technical information that flows on the global level, as it is difficult for the human intelligence to grasp them in general with breadth of scientific and technical activities, therefore, it looks to the future in the world of digital libraries and it requires concerted administrative efforts, and the use of strategic planning for recommendations:

- Digitization of library holdings and dissemination of traditional online in pre-planned stages with focus on the most important articles from printing documents and publications.

- Re-engineering design work procedures of administrative, regulatory and technical commensurate with the new digital environment.

- Necessity to take the necessary legal procedures with regard to maintain intellectual property rights of authors.

- University libraries with range of CDs university thesis have an urgent need to convert them into digital libraries in a separate digital library building with the full text and open them for public usage.

\section{Conclusion}

Digital libraries emerged as an obligatory result of revolution of the third millennium which is called the communications revolution, as libraries are able to prove that they are able to stand and cope with all the modern technology, where there is no conflict between the new and modern trends in libraries issue, but it also benefits from both of them concerning their evolution instruments in service for beneficiaries in every time and place. In spite of the non-achievement of available digital libraries to level of personal services that are offered by the traditional libraries because of the cheap cost, whereas they still attract a group of researchers as well as the scientists in medical and legal fields as a new class of beneficiaries.

\section{References}

Abdul Hameed, I. (2008). Digital libraries: A revolution in era of technology. Informatics Magazine, 25, 20-25.

Abdul Satar, M. (2004). Did the future of digital libraries change . Cyprarians Journal, Vol. 1.

Abu Izza, A. (2006). Trends of Arab researchers towards open archives and periodicals available free of charge through the Internet: Arab faculty members at the Sultan Qaboos University model. Cybrarians Journal, Vol. 6. Retrieved from http://www.cybrarians.info/journal/no10/openacess.htm

Abu Lofah, A. (2005). Transition to the digital library in banking institutions: A case study of reality of Central Bank of Libya library. Cyprarians journal, Vol 5.

Adam, R., \& Seamus, R. (2008). Ingest Strategies for Digital libraries: The Challenges of Handling Portable Objects. Paper presented at world library and information congress: 74th IFLA general conference and council 10-14 August, Quebec, Canada.

Alawi, H. (2007). Protection of intellectual property in the digital environment through the perspective of university professors. Cyprarians journal, Vol. 12.

Al-Jowheri, A., \& Al-Hazmi, G. (2008). Almadenah Digital Library: Reality and Future. Cyprarians Journal, Vol. 15.

Al-Khatib, N. (2001). Digitalization of intellectual production written in Arabic about strategy for entering the intellectual written production in Arabic for electronic space.

Al-Omran, H. (2010). Digital Library and Protection of Copyright and Intellectual Property. Informatics-Forums. Retrieved from http://maktabatsy.net/vb/showthread.php? $\mathrm{p}=9000$

Arms, W. Y. (1995). Key Concepts in the Architecture of the Digital Library. DLIB Magazine (July).

Arms, W. Y. (2000). The Web as an Open Access Digital Library. Retrieved from http://www.cs.cornell.edu/wya/papers/Kyoto-2000.doc

Atmizi, J. (2010). A flexible framework for evaluating the contents and activities of the electronic courses in support of the Arab universities. Cybrarians Journal, No. 19. Retrieved from http://journal.cybrarians.info/index.php?option=com_content\&view

Bouazza, M. (2006). Digital libraries and some intellectual issues. Journal of King Fahd National Library, Vol. 2. 
Choudhury, S., Hobbs, B., \& Lorie, M. (2002). A Framework for Evaluating Digital Library Services. Library Magazine, 8, 7-8. https://doi.org/10.1045/july2002-choudhury

Collier, M. (1997). Toward a general theory of the digital Library. A paper presented at ISDL97. Retrieved from http://ulisac.jp/ISDL/proceedings/collier.htm1

El Sayed, A. (2008). Self Archiving as a conduit for knowledge communication on the web: A study of its library and information applications. Fifth Conference of the Saudi Library and Information Society. Jeddah, 28-29 October 2008. The full edition of the "Arab Libraries and Information" magazine was published in the "Arab Libraries and Information” No. 2, p. 29, April 2009 - accessed 12 August 2018. References from http://www.knol.google.com/k

Faraj, A. (2005). Digital Libraries: Concepts and challenges and their impact on the profession of librarians between reality and idealism. Research presented at the crossroads of modern management $\mathrm{b}$ libraries techniques and information centers quality overall in period between December 18 to 20 Alexandrian, Egypt.

Faraj, A. (2009). Concepts in digital libraries. Department of Library and Information, University of Imam Muhammad bin Saud Islamic University.

Fox, E., \& Urs, S. (2002). Digital libraries. ARIST 36518.

Gladney, H., Ashany, R., Belkin, N., Zemankova, J. (1994). Digital Library: Gross Structure and Requirements. Report from a March 1994 Workshop.

Guendhilji, \& Al-Samarrai, A. (2004). Computerization of libraries. Amman, Dar Almaseerah.

Harley, D., Lawrence, S., Acord, S. K., \& Dixson, J. (2010). Affordable and Open Textbooks: An Exploratory Study of Faculty Attitudes. UC Berkeley: Center for Studies in Higher Education. Retrieved from http://escholarship.org/uc/item/1t8244nb

Hasinan, R. (2008). Digital Libraries: Planning and Requirements. Cyprarians journal, Vol. 15.

Keller, A. (2009). Establishing a digital library. Whitepaper sun Microsystems, 2 situation Report, Inc.

Meselhi, H. (2004). Did the future of digital libraries change. Cybrarians Journal, Vol. 1.

Moflih, F. (2008). Digital Libraries: Planning and implementation. King Fahad national library, No. 1.

Mustafa, A. (2009). Intellectual property rights and copyright in online environment. Cyprarians journal, Volume 21.

Rahouma, M. (2005). Internet and Social-Techno. Beirut: Center for Arab Unity Studies 2005.

Rosenberg, D. (2005). Towards the digital library: findings of an investigation to establish the current status of university libraries in Africa. International network for the availability of Scientific Publications (INASP), Oxford.

Saracevic, T. (2001). Digital library evaluation: Toward an evolution of concepts. Library Trends, 49(3), 350-369.

Shaheen, S. (2009). Initiatives of Free Access to Knowledge: A Documentary Study of the Frameworks for an Arab Initiative. Paper presented to the Third Arab Forum (Third Generation Technologies and its Inputs in the Library and Information Society) Cairo, 22-24 March 2009.

Wahdan, M. (2001). Financial protection of the right of the author. Alexandria: Dar Aljamaiyah Aljadeedah.

Yousef, H. (2005). Intellectual Property in the Digital Library Environment. Research presented to the Ninth Conference of Library and Information Professionals in Egypt from 28-30 June 2005 at Mubarak Saeed Library.

Zuhairi, T. (2004). Automated Systems for Information Retrieval. Amman, Dar Almaseerah.

\section{Copyrights}

Copyright for this article is retained by the author(s), with first publication rights granted to the journal.

This is an open-access article distributed under the terms and conditions of the Creative Commons Attribution license (http://creativecommons.org/licenses/by/4.0/). 